\title{
Efficacy of antibiotic-impregnated shunt versus conventional shunts to reduce cerebrospinal fluid infections in children: A systematic review and meta-analysis
}

\author{
YANZHAO QIU and YONGLIN WU
}

Department of Paediatrics, Huzhou Hospital of Traditional Chinese Medicine Affiliated Zhejiang
University of Traditional Chinese Medicine, Huzhou, Zhejiang 313000, P.R. China

Received January 2, 2020; Accepted April 13, 2020

DOI: $10.3892 / \mathrm{etm} .2020 .9122$

\begin{abstract}
Hydrocephalus is among the most common pediatric conditions treated by neurosurgeons. An antibiotic-impregnated shunt (AIS) was designed to reduce the rate of shunt infections. The objective of this systematic review and meta-analysis was to assess the efficiency of AIS in reducing the rate of shunt infection compared with standard shunts (SSs). A systematic search of PubMed, EMBASE, Medline, Cochrane Library, TRIP Database, CINAHL and Google Scholar databases was performed. Eligible studies included observational studies and randomized controlled trials (RCT) that compared the effects of AIS and SS for preventing shunt infections in pediatric patients. Twelve observational studies and one RCT conducted from January 2005 through October 2019 involving 7,952 pediatric patients were included in the analysis. The use of AIS significantly decreased the risk of CRI [risk ratio (RR) 0.42 ; $95 \%$ confidence interval: 0.33 to $0.53 ; \mathrm{P}<0.00001]$ with no statistical heterogeneity across the included studies $\left(\mathrm{I}^{2}=42 \%\right)$. This analysis demonstrates that the use of AIS significantly reduces the risk of shunt infection in pediatric patients.
\end{abstract}

\section{Introduction}

Hydrocephalus is the most common pediatric neurosurgical diagnosis, and the majority of patients require implantation of a cerebrospinal fluid diversion device, a shunt. Prevention of shunt infection is pivotal, since this could cause shunt malfunction, scarring and ventricular loculation with potentially devastating consequences for the patient (1-6). Furthermore, shunt

Correspondence to: Dr Yonglin Wu, Department of Paediatrics, Huzhou Hospital of Traditional Chinese Medicine Affiliated Zhejiang University of Traditional Chinese Medicine, 315 Nanjie Street, Huzhou, Zhejiang 313000, P.R. China

E-mail: ruoy250@163.com

Key words: antibiotic-impregnated shunt, conventional shunts, cerebrospinal fluid infection, meta-analysis infection is considered one of the most costly implant-related infections, with a cost of over 50,000 USD per infection in the United States (7).

The majority of shunt infections result from colonisation of the device by non-pathogenic gram-positive cocci, such as Staphylococcus epidermidis and S. aureus, and are acquired during surgery $(1,8,9)$. One approach to reducing shunt-related CSF infection is to use antibiotic-impregnated shunt (AIS) shunt catheters instead of a standard shunt (SS). AIS have been available for more than a decade, and contain $0.054 \%$ rifampin and $0.15 \%$ clindamycin, shown to effectively prevent colonization (10-12).

Several studies have been published to evaluate the effectiveness of AIS in reducing shunt infection in pediatric population compared to SS. The most recent meta-analysis by Klimo et al on this subject was published in 2014 (13). However, since then numerous new trials have been published comparing AIS with SS in pediatric patients.

A primary objective in the present study is to update the meta-analysis with systematic search of new studies comparing the use of AISs and SSs for the prevention of shunt infections in the pediatric population.

\section{Materials and methods}

Study design and search strategy. A search, systematic review and meta-analysis of eligible studies was conducted in the major databases (PubMed, EMBASE, Medline, Cochrane Library, TRIP Database, CINAHL and Google Scholar), using the MeSH or free text terms for all eligible articles published up to 31st October 2019. The search was restricted to studies performed on human pediatric subjects. No restriction on language or publication period was set. The reference lists from all the included studies were also searched for any additional eligible articles.

This systematic literature review was performed following the guidelines of the PRISMA statement (Preferred Reporting Items for Systematic Reviews and Meta-analyses) and Cochrane Handbook for Systematic Reviews of Intervention while using the following MeSH subject headings: ("cerebrospinal fluid shunts' OR ('cerebrospinal fluid' AND (shunt* OR catheter*) OR 'shunt system') AND ('antibiotic-impregnated' 


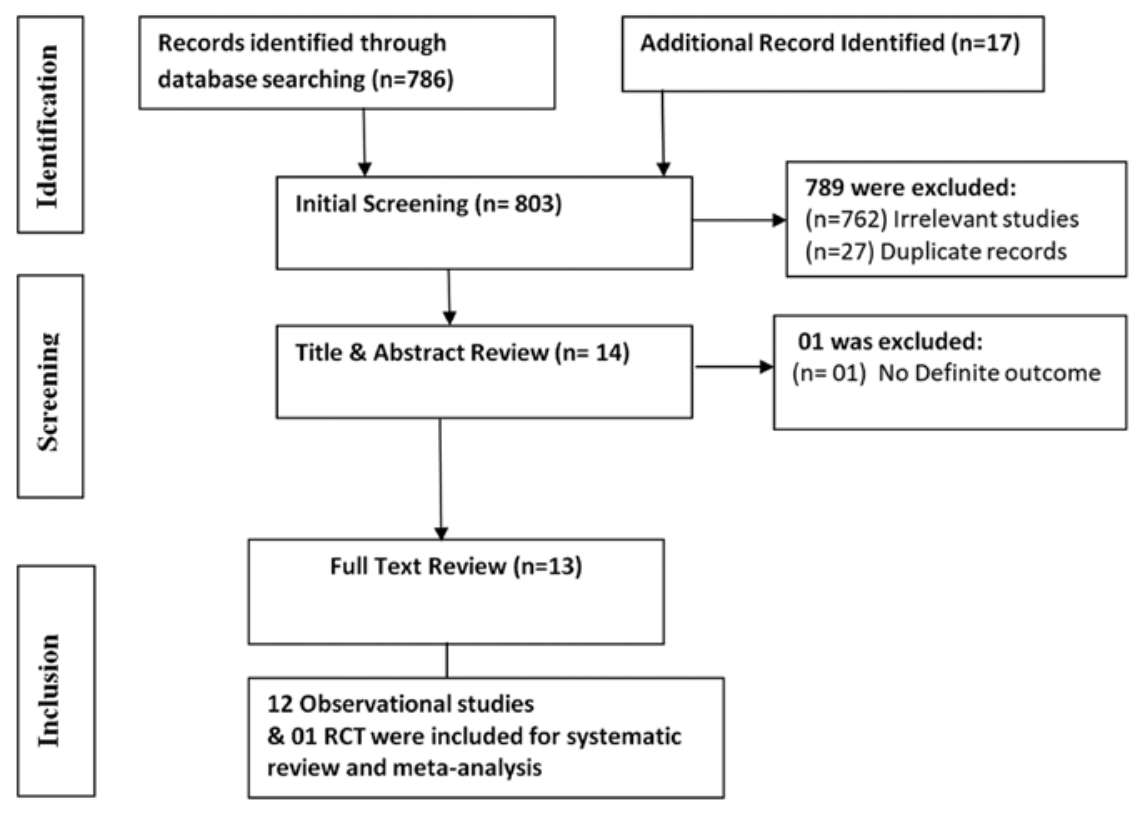

Figure 1. Flow diagram of the selection of studies and specific reasons for exclusion from the present meta-analysis. RCT, randomized controlled trials.

OR (antibiotic AND impregnated) OR Ventriculo-Peritoneal System AND infection.

Selection criteria. All studies comparing AISs and SSs in pediatric patients ( $<18$ years) were included. Duplicates, case reports, case series were excluded.

Risk of bias in individual studies. Missing data were requested from the original authors through electronic correspondence or mail. We examined the methodological quality of each study included in our meta-analysis by data on random assignment, treatment allocation concealment, group similarity at baseline, eligibility criteria specified, blinding, lost to follow up percentage and use of intention to treat analysis by using quality assessment scale. Two authors independently assessed the quality of included studies. Inconsistency over the quality scores was resolved by discussion among all the authors until subsequent agreement was reached. Missing data were requested from the original authors through electronic correspondence or mail. Publication bias was assessed by using the Begg's funnel plot analysis.

Data collection and analysis. The essential information was extracted carefully and independently from each included study by two authors: the first author's name, year of publication, age range of participants, number of participants (Antibiotic Impregnated Shunt/Conventional Shunt group), number of procedures, number of infections and Quality Score. Any disagreement was resolved by discussion.

Statistical analysis. Pooled risk ratio (RR) with 95\% confidence intervals (CIs) and publication bias were calculated using Review Manager Statistical Software [RevMan, version 5.3; Nordic Cochrane Centre (Cochrane Collaboration), Copenhagen, Denmark; 2014]. We investigated the presence of heterogeneity of the included studies by using the Cochran's $\mathrm{Q}$ statistic and $\mathrm{I}^{2}$ metric tests. If the $\mathrm{I}^{2}$ was $<50 \%$ then a fixed-effects model was used, otherwise a random-effects model was used to combine the results.

\section{Results}

Identification of relevant studies. A total of 803 published articles were retrieved from the systematic search during the initial screening (Fig. 1). Out of this number, 789 studies were excluded because of irrelevancy $(n=762)$, and duplicate records $(n=27)$. One additional study was excluded after title and abstract review due to lack of definite outcome $(n=1)$. Thus, a total of 12 observational studies and one randomized controlled trial (RCT) were included for systematic review and meta-analysis.

Characteristics of eligible studies. Table I summarizes the characteristics of the selected studies, including number of participants, age group, number of surgical procedures, number of CSF infections, and study conclusions. There were a total of 2,860 pediatric patients in the AIS stunt group, and 5,092 pediatric patients in the SS group, with a number of patients in each study ranging from 11 to 1,963 . Two of the studies, by Mallucci et al (14) and Eymann et al (18) included, not only pediatric, but also adult patients, and separate data are reported for these two groups $(13,14)$. Twelve of the 13 included studies were single-institution, while one study, by Hayhurst et al was a retrospective multicentric cohort study (15). Studies were published between January 2005 and October 2019.

Meta-analysis: shunt-related CSF infections. There was a total of 463 CSF infections reported in the selected observational studies (16-26). Of these, 366 were associated with the use of SS, yielding an infection rate of $7.48 \%$. In the pediatric patients receiving AIS, 97 CSF infections were reported, with an infection rate of $3.65 \%$. Four infection events associated with the use of SS, and three events, associated with the use 


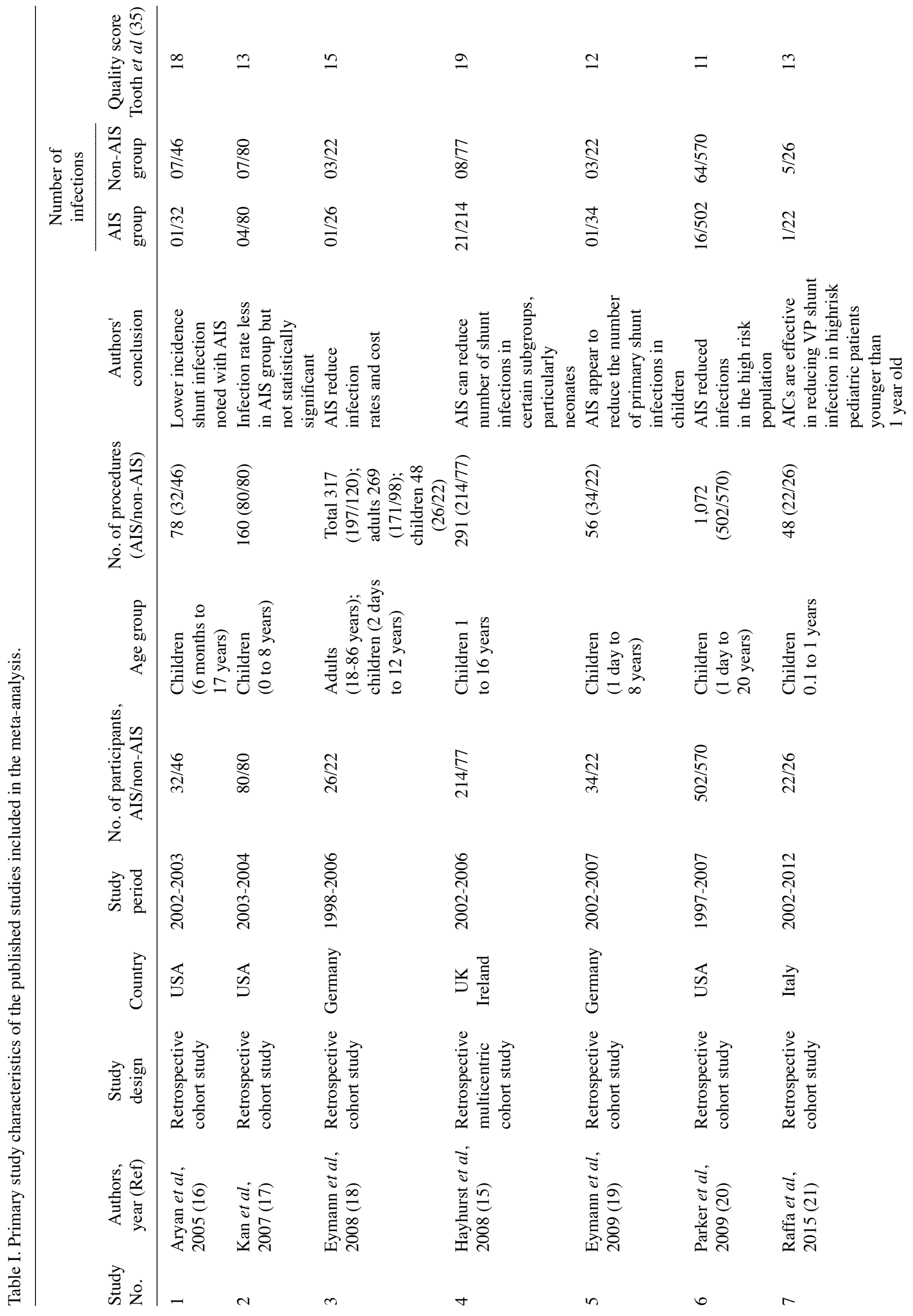




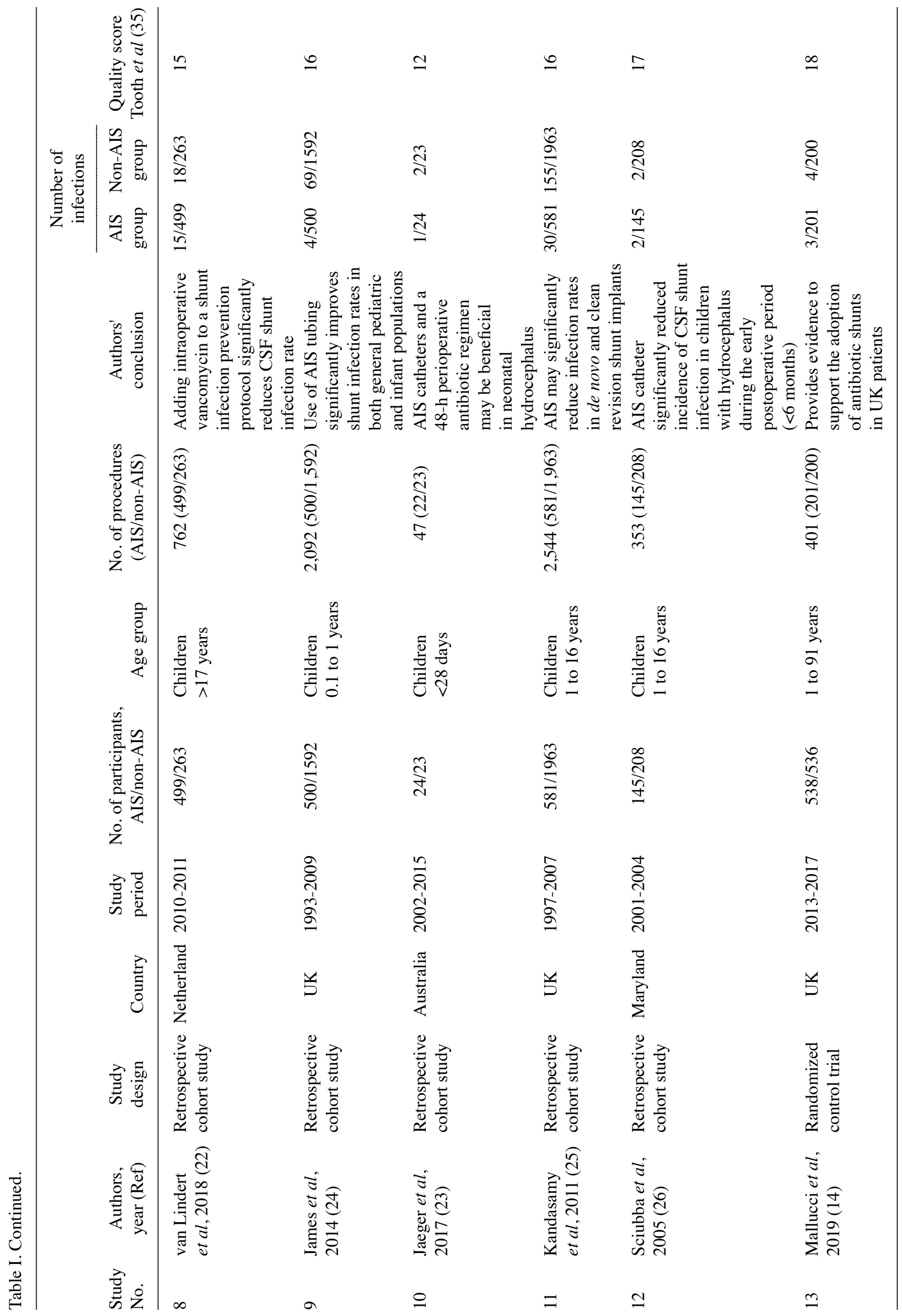




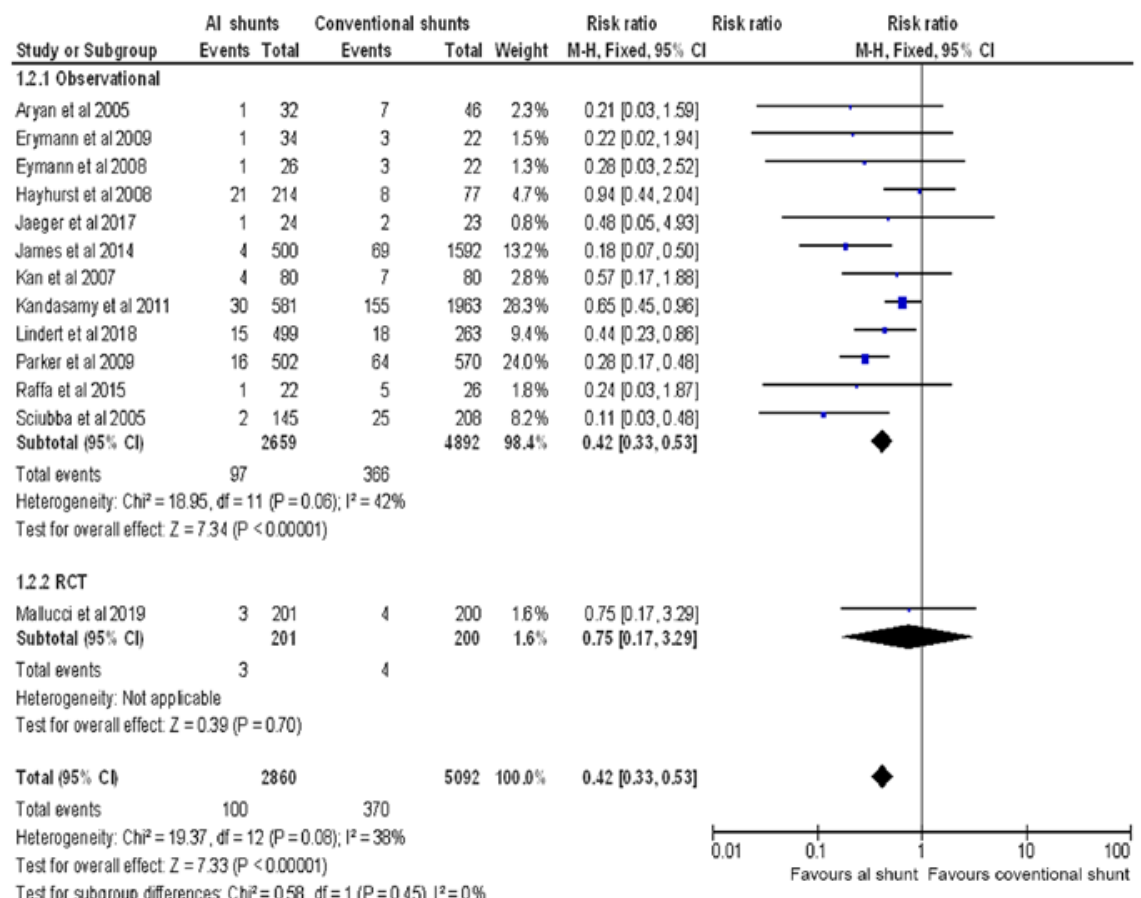

Figure 2. Forest plot for antibiotic-impregnated shunt systems versus conventional shunt systems to reduce cerebrospinal fluid infections in children based on the fixed effect model. RCT, randomized controlled trials; CI, confidence interval.

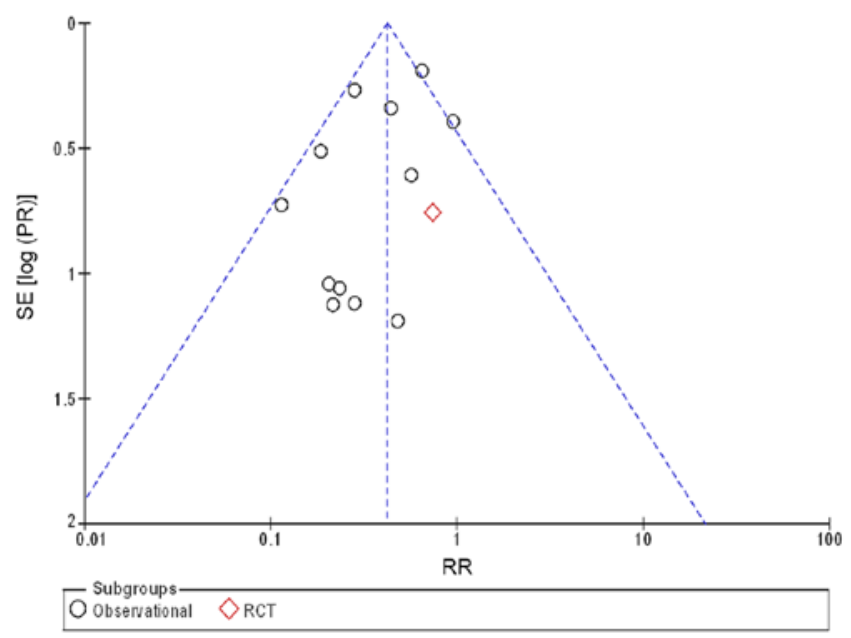

Figure 3. Begg's funnel plot for the studies included in meta-analysis for antibiotic-impregnated shunt systems versus conventional shunt systems to reduce cerebrospinal fluid infections in children based on the fixed effect model. RR, risk ratio; RCT, randomized controlled trials.

of AIS were reported in the selected RCT (14), yielding an infection rate of 2 - and $1.4 \%$, respectively (Fig. 2). The overall pooled RR of CSF infection using a fixed effects model was 0.42 (95\% CI: 0.33 to $0.53 ; \mathrm{P}<0.00001)$ with no statistical heterogeneity across the included studies $\left(\mathrm{I}^{2}=42 \%\right)$ (Fig. 2$)$.

These results indicated a significant decrease in CSF infection rates in the AIS group. All 13 included studies provide sufficient details of an adequate method of allocation concealment and blinding. Begg's funnel plots were used to assess the potential selection and performance publication bias. As shown in Fig. 3, the shape of the funnel plot suggests the absence of publication bias.

\section{Discussion}

In this meta-analysis, we found that the use of AIS in pediatric patients was associated with a decreased risk of CSF infection. A SS, consisting of silastic ventricular and peritoneal catheters, is an effective treatment for hydrocephalus (27). However, due to CSF shunt complications, such as shunt failure and infection, SS placement often requires revision surgery, With infection rates approximately 3 -fold higher after a first revision and their frequency increasing with each additional procedure (28). AISs have been introduced to prevent CSF infections, especially in the early postoperative period (10-12). Of the13 studies included in the analysis, 8 reported statistically significant reduction in CSF infections associated with the use of AIS (18-22,24-26).

In one of the earliest studies comparing AIS and SS groups of pediatric patients, Sciubba et al (26) reported that AIS was associated with significant reduction in CSF infection rates in children with hydrocephalus during the early postoperative period ( $<6$ months). This was subsequently confirmed by Klimo et al (13), albeit AIS in the study of Sciubba et al (26) was independently associated with a 2.4-fold decreased likelihood of shunt infection. James et al compared an AIS study group with historical cohort of SS procedures, and identified a significant reduction in CSF infection rates in pediatric patients (24). At the same time, they reported an increased rate of CSF infections in revision surgery in the AIS group, thus questioning the efficiency of AIS for long-term use (24).

The study of Eymann et al (18) included both adult and pediatric patients, and showed that the infection rates were 2.18-fold higher with SS than with AIS. Similarly, in a subsequent study by the same group (19), which included 56 pediatric patients, risk score for shunt infections was significantly 
higher in the AIS study group than in the SS control group. In a large multicenter study Kandasamy et al reported that AIS significantly reduced CSF infection rates in de novo and clean revision shunt implants, despite an apparent overlap of confidence intervals in the results from various sites (25). In a retrospective cohort study, van Lindert et al used vancomycin antibiotic solution to drench and flush the shunt and fill the shunt reservoir instead of using AIS, and reported a significant decrease in infection rates (an absolute risk reduction of $3.8 \%$, and relative risk reduction of 56\%) in antibiotic-treated shunt group of pediatric patients, as well as an increase in time from surgery to infection (22).

In their retrospective study, Parker et al examined CSF infections in several groups of patients with high-risk factors [prematurity, post-meningitis, conversion of external ventricular drains (EVD), prolonged hospital stay]. In all high-risk groups AIS was associated with significantly reduced rates of shunt infections (20).

A study by Raffa et al reported for the first time the effectiveness of AIS in reducing VP shunt infection in high-risk pediatric patients <1-year-old. Additionally, AIS had a protective effect against shunt infections in all the specific high-risk subgroups, such as preterm newborns, children with post-hemorrhagic or post-infective hydrocephalus, and children with a previous EVD (21).

Five of the 13 studies included in this meta-analysis presented negative statistical findings. While Aryan et al did not identify a statistically significant difference in infection rates between the AIS and SS groups, they report protective benefits of AIS compared to SS (16). Similarly, in a study by Kan and Kestle, there was no difference in the shunt infection rate between groups, even when adjusted for age, medical history, diagnosis, and previous infections (17). In a retrospective cohort study of neonates ( $<28$ days), Jaeger et al reported a statistically significantly delayed median time interval between insertion and revision in the AIS group, while an overall rate of CSF infection was unaffected (23).

In the only included RCT by Mallucci et al, AIS was associated with a 3 -fold decrease in shunt revisions. Although that study included both pediatric and adult patients, it strongly supported the use of AIS in patients undergoing their first shunt insertion (14).

The limitations of the current meta-analysis arise among others from heterogeneity of the included studies. While most of the studies included only pediatric patients, others included both children and adults $(14,18)$, and a definition of a shunt infection may vary from study to study. There is also a variety of confounders for shunt infections, such as age and prematurity (29-31), gender (28), former shunt and systemic infections $(32,33)$, previous revisions, extended hospital stay, positive CSF cultures prior to implantation, and the preoperative occurrence of CSF leakage or the use of an EVD (10). While prospective, blinded, RCT may provide more balanced information, such studies would not be cost-effective, and would require very large patient numbers, multicenter cooperation, and development of standard protocols (34).

Our analysis shows that AISs can substantially reduce the risk of shunt infections. AIS, therefore, may be beneficial for all pediatric patients with hydrocephalus who require a shunt.

\section{Acknowledgements}

Not applicable.

\section{Funding}

No funding was received.

\section{Availability of data and materials}

The datasets used and/or analyzed during the current study are available from the corresponding author on reasonable request.

\section{Authors' contributions}

YQ designed the paper. YQ and YW were involved in literature search and data interpretation. YQ was responsible for the data analysis and prepared the manuscript. YW edited the manuscript. Both authors have read and approved the final manuscript.

\section{Ethics approval and consent to participate}

Not applicable.

\section{Patient consent for publication}

Not applicable.

\section{Competing interests}

The authors declare that they have no competing interests.

\section{References}

1. Choux M, Genitori L, Lang D and Lena G: Shunt implantation: Reducing the incidence of shunt infection. J Neurosurg 77: 875-880, 1992.

2. Jamjoom AB, Mohammed AA, al-Boukai A, Jamjoom ZA Rahman N and Jamjoom HT: Multiloculated hydrocephalus related to cerebrospinal fluid shunt infection. Acta Neurochir (Wien) 138: 714-719, 1996.

3. Vanaclocha V, Sáiz-Sapena $\mathrm{N}$ and Leiva J: Shunt malfunction in relation to shunt infection. Acta Neurochir (Wien) 138: 829-834, 1996.

4. Walters BC, Hoffman HJ, Hendrick EB and Humphreys RP: Cerebrospinal fluid shunt infection. Influences on initial management and subsequent outcome. J Neurosurg 60: 1014-1021, 1984.

5. Chadduck $\mathrm{W}$ and Adametz J: Incidence of seizures in patients with myelomeningocele: A multifactorial analysis. Surg Neurol 30: 281-285, 1988.

6. Liao F, Li G, Yuan W, Chen Y, Zuo Y, Rashid K, Zhang JH, Feng $\mathrm{H}$ and Liu F: LSKL peptide alleviates subarachnoid fibrosis and hydrocephalus by inhibiting TSP1-mediated TGF- $\beta 1$ signaling activity following subarachnoid hemorrhage in rats. Exp Ther Med 12: 2537-2543, 2016.

7. Darouiche RO: Treatment of infections associated with surgical implants. N Engl J Med 350: 1422-1429, 2004.

8. Kestle JRW, Hoffman HJ, Soloniuk D, Humphreys RP, Drake JM and Hendrick EB: A concerted effort to prevent shunt infection. Childs Nerv Syst 9: 163-165, 1993.

9. Kestle JRW, Riva-Cambrin J, Wellons JC III, Kulkarni AV, Whitehead WE, Walker ML, Oakes WJ, Drake JM, Luerssen TG, Simon TD, et al; Hydrocephalus Clinical Research Network: A standardized protocol to reduce cerebrospinal fluid shunt infection: The Hydrocephalus Clinical Research Network Quality Improvement Initiative. J Neurosurg Pediatr 8: 22-29, 2011. 
10. Pattavilakom A, Kotasnas D, Korman TM, Xenos C and Danks A: Duration of in vivo antimicrobial activity of antibioticimpregnated cerebrospinal fluid catheters. Neurosurgery 58 930-935, discussion 930-935, 2006

11. Bayston R: Duration of in vivo antimicrobial activity of antibioticimpregnated cerebrospinal fluid catheters. Neurosurgery 60 E208, author reply E208, 2007.

12. Bayston R, Ashraf $\mathrm{W}$ and Bhundia C: Mode of action of an antimicrobial biomaterial for use in hydrocephalus shunts. J Antimicrob Chemother 53: 778-782, 2004.

13. Klimo P Jr, Van Poppel M, Thompson CJ, Baird LC, Duhaime AC and Flannery AM; Pediatric Hydrocephalus Systematic Review and Evidence-Based Guidelines Task Force: Pediatric hydrocephalus: systematic literature review and evidence-based guidelines. Part 6: Preoperative antibiotics for shunt surgery in children with hydrocephalus: a systematic review and meta-analysis. J Neurosurg Pediatr 14 (Suppl 1): 44-52, 2014.

14. Mallucci CL, Jenkinson MD, Conroy EJ, Hartley JC, Brown M, Dalton J, Kearns T, Moitt T, Griffiths MJ, Culeddu G, et al BASICS Study collaborators: Antibiotic or silver versus standard ventriculoperitoneal shunts (BASICS): A multicentre, single-blinded, randomised trial and economic evaluation. Lancet 394: 1530-1539, 2019.

15. Hayhurst C, Cooke R, Williams D, Kandasamy J, O'Brien DF and Mallucci CL: The impact of antibiotic-impregnated catheters on shunt infection in children and neonates. Childs Nerv Syst 24 557-562, 2008

16. Aryan HE, Meltzer HS, Park MS, Bennett RL, Jandial R and Levy ML: Initial experience with antibiotic-impregnated silicone catheters for shunting of cerebrospinal fluid in children. Childs Nerv Syst 21: 56-61, 2005.

17. Kan P and Kestle J: Lack of efficacy of antibiotic-impregnated shunt systems in preventing shunt infections in children. Childs Nerv Syst 23: 773-777, 2007.

18. Eymann R, Chehab S, Strowitzki M, Steudel W-I and Kiefer M: Clinical and economic consequences of antibiotic-impregnated cerebrospinal fluid shunt catheters. J Neurosurg Pediatr 1 : 444-450, 2008

19. Eymann R, Steudel W-I and Kiefer M: Infection rate with application of an antibiotic-impregnated catheter for shunt implantation in children - a retrospective analysis. Klin Padiatr 221: 69-73, 2009.

20. Parker SL, Attenello FJ, Sciubba DM, Garces-Ambrossi GL, Ahn E, Weingart J, Carson B and Jallo GI: Comparison of shunt infection incidence in high-risk subgroups receiving antibiotic-impregnated versus standard shunts. Childs Nerv Syst 25 77-83, discussion 85, 2009.

21. Raffa G, Marseglia L, Gitto E and Germanò A: Antibiotic-impregnated catheters reduce ventriculoperitoneal shunt infection rate in high-risk newborns and infants. Childs Nerv Syst 31: 1129-1138, 2015.

22. van Lindert EJ, Bilsen MV, Flier MV, Kolwijck E, Delye H and Oever JT: Topical vancomycin reduces the cerebrospinal fluid shunt infection rate: A retrospective cohort study. PLoS One 13: e0190249, 2018
23. Jaeger W, Lee S, Vineet D, Keil A, Agarwal N and Rao S: Ventriculoperitoneal shunts in neonates: A retrospective study of outcomes with antibiotic-impregnated catheters and a modified peri-operative antibiotic protocol. Br J Neurosurg 31: 672-676, 2017.

24. James G, Hartley JC, Morgan RD and Ternier J: Effect of introduction of antibiotic-impregnated shunt catheters on cerebrospinal fluid shunt infection in children: A large single-center retrospective study. J Neurosurg Pediatr 13: 101-106, 2014.

25. Kandasamy J, Dwan K, Hartley JC, Jenkinson MD, Hayhurst C, Gatscher S, Thompson D, Crimmins D and Mallucci C: Antibiotic-impregnated ventriculoperitoneal shunts - a multi-centre British paediatric neurosurgery group (BPNG) study using historical controls. Childs Nerv Syst 27: 575-581, 2011.

26. Sciubba DM, Kretzer RM and Wang PP: Acute intracranial subdural hematoma following a lumbar CSF leak caused by spine surgery. Spine 30: E730-E732, 2005.

27. Bondurant CP and Jimenez DF: Epidemiology of cerebrospinal fluid shunting. Pediatr Neurosurg 23: 254-258, discussion 259 , 1995.

28. Simon TD, Whitlock KB, Riva-Cambrin J, Kestle JR, Rosenfeld M, Dean JM, Holubkov R, Langley $M$ and Hamblett NM: Revision surgeries are associated with significant increased risk of subsequent cerebrospinal fluid shunt infection. Pediatr Infect Dis J 31: 551-556, 2012.

29. Fulkerson DH, Vachhrajani S, Bohnstedt BN, Patel NB, Patel AJ, Fox BD, Jea A and Boaz JC: Analysis of the risk of shunt failure or infection related to cerebrospinal fluid cell count, protein level, and glucose levels in low-birth-weight premature infants with posthemorrhagic hydrocephalus. J Neurosurg Pediatr 7: 147-151, 2011.

30. Pople IK, Bayston R and Hayward RD: Infection of cerebrospinal fluid shunts in infants: A study of etiological factors. J Neurosurg 77: 29-36, 1992

31. Enger PØ, Svendsen F and Wester K: CSF shunt infections in children: Experiences from a population-based study. Acta Neurochir (Wien) 145: 243-248, discussion 248, 2003.

32. Ritz R, Roser F, Morgalla M, Dietz K, Tatagiba M and Will BE: Do antibiotic-impregnated shunts in hydrocephalus therapy reduce the risk of infection? An observational study in 258 patients. BMC Infect Dis 7: 38, 2007.

33. Peng J, Deng X, He F, Omran A, Zhang C, Yin F and Liu J: Role of ventriculoperitoneal shunt surgery in grade IV tubercular meningitis with hydrocephalus. Childs Nerv Syst 28: 209-215, 2012.

34. Richards HK, Seeley HM and Pickard JD: Efficacy of antibiotic-impregnated shunt catheters in reducing shunt infection: Data from the United Kingdom Shunt Registry. J Neurosurg Pediatr 4: 389-393, 2009.

35. Tooth L, Ware R, Bain C, Purdie DM and Dobson A: Quality of reporting of observational longitudinal research. Am J Epidemiol 161: 280-288, 2005.

This work is licensed under a Creative Commons Attribution-NonCommercial-NoDerivatives 4.0 International (CC BY-NC-ND 4.0) License. 